\title{
Women's employment and family planning in rural Uganda
}

\section{Goedele Van den Broeck}

To cite this article: Goedele Van den Broeck (2019): Women's employment and family planning in rural Uganda, Women \& Health, DOI: 10.1080/03630242.2019.1671948

To link to this article: https://doi.org/10.1080/03630242.2019.1671948

曲 Published online: 06 Oct 2019.

Submit your article to this journal ${ }^{\pi}$

Q View related articles $\sqsubset$

View Crossmark data $\nearrow$ 


\title{
Women's employment and family planning in rural Uganda
}

\author{
Goedele Van den Broeck (1) \\ Division of Bio-Economics, Department of Earth and Environmental Sciences, KU Leuven, Leuven, Belgium
}

\begin{abstract}
Despite impressive progress in increasing contraceptive use in developing countries during recent decades, the uptake has lagged behind in Africa. One of the most critical factors in raising the use of contraception is women's employment status. This study analyzed the link between women's employment and family planning in rural Uganda and addressed shortcomings in the literature by using nationally representative panel data from the 2010 and 2012 rounds of the Uganda National Panel Survey for 800 women aged 15-49 years, and estimating heterogeneous effects for different types of employment and across socioeconomic characteristics. Employment was not associated with greater use of modern contraceptives, but off-farm wage-employed women were more likely to use traditional contraception. The correlation of employment was strongest for women who had reached their desired fertility status, but became insignificant for poorer women who lived in remote areas. However, likely due to the ineffectiveness of traditional methods, off-farm wage employment was not associated with greater spacing between births. Our findings implied that providing rural employment opportunities for women is insufficient to increase the uptake of modern contraceptives. To enhance the effectiveness of family planning programs, health-care officers should target off-farm wage-employed women to address their unmet contraceptive needs.
\end{abstract}

\section{ARTICLE HISTORY}

Received 21 February 2019

Revised 23 August 2019

Accepted 28 August 2019

\section{KEYWORDS}

Contraceptive use; employment; family planning; fertility; SubSaharan Africa; Uganda

\section{Introduction}

Family planning is considered as a prerequisite to reduce child and maternal mortality, slow down rapid population growth, and ultimately eradicate poverty (Canning and Schultz 2012). During recent decades, impressive progress has been realized in increasing the uptake of contraceptives in developing countries (UN 2015). Yet, large disparities across regions still exist. Contraceptive use is particularly low in Africa, where only $33 \%$ of married women use any birth control method, compared to $64 \%$ of married women worldwide in 2015. Unmet need for contraception is accordingly the highest in Africa, where $24 \%$ of married women who want to prevent pregnancy do not have access to contraception (UN 2015). To reach the targets of Sustainable Development Goal 3 on the reduction of child and maternal mortality by 2030, we need a better understanding of the drivers of family planning in Africa.

An extensive body of literature has examined the factors associated with family planning decisions in developing countries (see recent reviews by Prata et al. (2017) and James-Hawkins

CONTACT Goedele Van den Broeck goedele.vandenbroeck@uclouvain.be $\mathbf{E}$ Earth and Life Institute, Université catholique de Louvain, Louvain-la-Neuve, Belgium

Color versions of one or more of the figures in the article can be found online at www.tandfonline.com/wwah. 
et al. (2018)). One factor that is considered to be crucial in increasing the demand for contraceptive use and reducing fertility is women's employment status. Theoretically, employment might affect family planning through 1) higher total household income, which may reduce or increase the need for family planning, depending on spouses' preferences; 2) an increased share of women's income over total income, which may lead to a higher autonomy of women within the household and likely increase the need for family planning; and 3) a higher opportunity cost for raising children, which increases the need for family planning (Van den Broeck and Maertens 2015). Assuming that women are not financially/socially constrained in obtaining contraceptives in (local) health facilities, employment might thus lead to a lower number of children or greater spacing between births. This link has been thoroughly investigated and documented for industrialized countries, particularly during periods when women's participation in the labor market rapidly increased (Brewster and Rindfuss 2000; Goldscheider, Bernhardt, and Lappegard 2015).

However, for developing countries and particularly for Africa, the link between women's employment and family planning might be different. First, the relation depends on the type of employment. Women's employment in rural areas often entails informal, unpaid work on their own household-farm. As off-farm employment is characterized by higher labor productivity than on-farm employment (McCullough 2017), and women have a greater say over their own off-farm earnings than pooled on-farm earnings (documented for Ethiopia by Tigabu and Villanger (2017) and for Tanzania by Vyas, Mbwambo and Heise (2015)), off-farm employment may lead to a higher demand for family planning than on-farm employment. Yet, if women take up low-remunerative off-farm jobs to smooth negative household income shocks, off-farm employment will not alter the need for family planning. In addition, self-employment is the most common type of women's work in rural areas, which allows women to take care of their children while working at the same time (Van den Broeck and Kilic 2019). In this case, opportunity costs for raising children do not increase, which is in contrast with wage employment in which women are often not allowed to bring their children along. Therefore, off-farm wage employment might lead to a higher demand for family planning than off-farm selfemployment.

Second, the relation between women's employment and family planning depends on the type of contraception. Most studies have focused on the use of modern contraceptives, as these are the most effective form of preventing pregnancies. However, access to modern contraceptives might be problematic, especially in rural areas. The quality of family planning services is often insufficient to reduce unmet need for contraception, as new contraceptive users are not reached or current users are not sustained (Fruhauf et al. 2018). If access is insufficient, employment will not increase the use of modern contraceptives, even if it alters the need for family planning. On the other hand, it might increase the uptake of traditional contraception, such as abstinence and withdrawal. Women may prefer traditional methods over modern methods, which is not only due to poor access to the latter, but also because of fear of side effects (Ajayi, Adeniyi, and Akpan 2018). This is not limited to uneducated, poor women, but might reflect a broader view of society on contraceptive behavior and reproductive health choices women make (Rossier and Corker 2017). Yet, given the lower effectiveness of traditional contraception, women's employment might lead to a higher uptake of such methods but not necessarily to an actual reduction in the number of children or to greater spacing between births. 
Despite these arguments that women's employment does not lead automatically to increased family planning, many empirical studies have demonstrated such an effect. However, this literature is characterized by three main limitations. First, some studies have focused on specific case studies in which a sudden boom in the creation of off-farm employment opportunities for women took place, which drastically altered women's fertility decisions (Jensen 2012; Van den Broeck and Maertens 2015). While such cases are highly informative, they are quite rare, occur in specific regions, and are not likely to hold for entire populations. Second, most studies have been based on cross-sectional data (e.g. Assefa and Tadesse 2017; Tiruneh et al. 2016; Wado 2017). Such evidence might suffer from bias due to reverse causality, which may overestimate the effect of employment. Third, most studies did not distinguish between rural and urban areas or between different types of employment and assumed an average effect that holds for the entire population. However, a large heterogeneity might exist within a population, and employment might be more effective in increasing contraceptive use among specific groups of women.

We studied the link between women's employment status and their family planning decisions in rural Uganda. We addressed the above-mentioned shortcomings and contributed to the literature in three main ways. First, we used nationally representative data from a balanced panel of 800 women and two survey rounds conducted in 2010 and 2012. Second, we explicitly distinguished between on-farm, off-farm wage, and off-farm self-employment to compare whether different types of employment led to different effects. In addition, we specified family planning in various ways to capture different aspects: childbirth or pregnancy during the two survey rounds, application of traditional contraceptive methods, and use of modern contraceptives. Third, we analyzed several interactive effects to unravel whether employment was more strongly associated with the family planning decisions of certain groups of women. The data and analyses allowed us to draw more nuanced conclusions about the relationship between women's employment and family planning in rural areas in developing countries.

Our focus on rural Uganda is relevant for several reasons. Uganda ranks in the top 10 countries for the highest fertility rates in the world, with a total fertility rate of 5.9 children per woman in rural areas in 2016 (UBoS and ICF 2018). Twenty-eight percent of married women have an unmet need for contraception, and child and maternal mortality were 6,400 and 336 deaths, respectively, per 100,000 live births during 2011-2016. The persistent high fertility rates have been attributed to misconceptions and fears related to contraception, power relations between spouses, socio-cultural expectations for large family sizes, and health service barriers (Kabagenyi et al. 2014; Nalwadda et al. 2010). Especially in rural areas, access to contraception lags behind. Until recently, Uganda's government had invested little in family planning programs (Bongaarts 2014). However, at the 2012 Family Planning Summit in London, the government committed to reduce unmet need for family planning to $10 \%$ and to increase the use of modern contraceptives to $50 \%$ by 2020 (Government of Uganda 2017). To reach this target, significant efforts need to be made. The findings of this study could help policymakers to evaluate the most effective factors to enhance the use of birth control and to assess the role of women's employment in making family planning decisions. 


\section{Data and methods}

\section{Data source}

We used nationally representative data from the Uganda National Panel Survey (UNPS), which is generated as part of the World Bank Living Standards Measurement Study (LSMS-ISA) initiative ${ }^{1}$. The analysis relied on two survey rounds implemented among 3,123 households in 2010 and 2,716 households in $2012^{2}$. At baseline, the survey was designed to be representative at the national, urban/rural and regional levels. A two-stage sampling design based on a population census was used to draw the sample. In the first stage, enumeration areas (EAs) were drawn with probability proportional to size, and in the second stage, households were drawn using simple random sampling. In 2012, the same households were interviewed again, including individuals who left the original household and started a new household. No information was available on household survey participation rates, but generally these rates tend to be high in developing countries (Lupu and Michelitch 2018). More specific details about the survey were provided by UBoS (2010).

The use of the 2010-2012 UNPS data entailed several advantages: data were collected at the individual-level; sampled households and individuals were tracked over time; and the multi-topic questionnaire included extensive modules on different types of labor (i.e., farm employment, off-farm wage employment and employment in household non-farm enterprises) and on women's knowledge and use of contraceptive methods. The latter module was personally addressed to all the women in the household who were between 15 and 49 years old. The questionnaire package also included a community questionnaire administered at the EA level, collecting data on services, infrastructure, and institutions from a focus group of community leaders.

\section{Study participants}

Our population of interest was married women aged 15-49 years throughout the period 2010-2012. We focused on women living in rural areas who were married to the household head. The latter restriction was needed to obtain information about the husband because this was not collected for women who were married to other men in the household. For the 2010 round, 1,269 women fulfilled these requirements, and $89.1 \%$ of these responded, while the response rate was $82.9 \%$ for 1,331 women in the 2012 round. We retained in the analyses women for whom we had two observations over time to draw better causal conclusions. The final sample included 800 women (70.8\% retention from the first round and $72.5 \%$ from the second round) who were observed both in 2010 and 2012.

\section{Ethics statement}

The surveys were implemented by the Uganda Bureau of Statistics (UBoS) through the Division for Socioeconomic Surveys. The UBoS has a national mandate to collect population statistics and is not subject to an Institutional Review Board (IRB) approval to conduct the survey. Nevertheless, all study participants were asked for informed consent after the enumerators carefully explained the purpose of the study. 
Participation in the study was on a voluntary basis, and the study participants did not face any significant physical or psychological risks during the survey. All possible identifiers have been removed from the data to ensure the anonymity of the respondents.

\section{Study variables}

The outcome variable of this study was women's family planning status in 2012. We used two different specifications: 1) a binary variable taking the value of one if the woman gave birth between 2010 and 2012 or if she was pregnant at the time of the 2012 survey; and 2) a categorical variable with three levels that described which contraception was used in 2012. The base level entailed no contraception, the second level entailed only traditional contraception, including the rhythm method and withdrawal, and the third level entailed modern contraception, including sterilization, intra-uterine devices (IUDs), implants, injectables, pills, condoms, diaphragm, foam, standard days method and emergency contraception $^{3}$.

The main independent variable of interest was women's employment status in 2010. We used two different specifications: 1) a binary variable taking the value of one if the woman was employed during the past 12 months before the 2010 survey; and 2) a categorical variable with four levels, for which the base level was specified as being unemployed during the past 12 months before the 2010 survey, the second level as on-farm employed, the third level as off-farm wage employed and the fourth level as off-farm self-employed. The four levels were mutually exclusive: if a woman was off-farm employed, even for a short period, she was automatically assigned to either off-farm wage or off-farm self-employment. If a woman was both wage and self-employed, she was assigned to the type of employment on which she spent most of her time.

\section{Data analysis}

First, we used a bivariate analysis to test whether differences were statistically significant between unemployed and employed women (using two-sided t-tests), and between on-farm employed and off-farm wage/self-employed women (using chi-square tests). Second, we used two multivariate analyses: 1) a binary logistic model to investigate the relation of employment status to the probability of giving birth between 2010 and 2012 or being pregnant in 2012, and 2) a multinomial logistic model to investigate the relation of employment status to contraceptive use in 2012. In both models, we analyzed two employment specifications, one for overall employment status and one for specific employment type. The sample of the first model included 800 women, while we excluded pregnant women in the second model as contraceptive use was not applicable to them, which reduced the sample size to 674 women $(84.3 \%$ of the initial sample) for the second model.

In each multivariate model, we included a large vector of control variables that might be associated with family planning decisions. We included individual-level characteristics (age, education, total number of (deceased) children and whether the woman gave recently birth), husband-level characteristics (age, education and presence in household), household-level characteristics (polygynous union and wealth), proxies for supply of contraceptives (distance to nearest town, presence of health center in community and access to free contraceptives in nearest health center) and region dummies. The wealth variable was constructed using a factor 
analysis of dwelling attributes and durable assets. We did not include ethnicity as a control variable as nearly 50 ethnicities exist in Uganda, all of them highly correlated with region. The variables initially included in the multivariable regression modes were selected based on the literature (Sano et al. 2018; Tiruneh et al. 2016; Wado 2017; Westeneng and D'Exelle 2015), and we retained those based on the correlation at the bivariate level $(p<.1)$ with the outcome variables (i.e., family planning decisions) and with the main independent variable of interest (i.e., women's employment status).

We used two criteria to assess the fit of the models: 1) the likelihood ratio chi-square value to test the null hypothesis that all covariates could be jointly excluded from the model; and 2) the Hosmer-Lemeshow chi-square value to test the null hypothesis that the observed values were equal to the predicted values. All models performed well according to these two tests.

Third, we analyzed interactive effects to unravel whether the relation between employment and use of contraception differed across different types of women. We re-estimated the logistic models and interacted the employment status with several demographic characteristics, including women's age, previous fertility, wealth and remoteness of the village. To ease interpretation, we presented the interactive effects graphically.

\section{Controlling for potential bias}

We controlled for two main sources of potential bias that might lead to an over- or underestimation of the relation of employment to family planning. First, employment status does not only affect family planning; it might also be affected by family planning. To control for this potential reverse causality, we estimated the relation of the employment status in 2010 to family planning status in 2012. We also used the 2010 values for the control variables.

Second, the attrition rate between the two rounds was $18.5 \%$. If women's employment status was correlated with the likelihood of being re-interviewed (e.g., because employed women more likely migrated or were working elsewhere at the moment of the survey), attrition bias might affect the estimation of the relation of employment. To correct for potential attrition bias, we analyzed a logistic model with a binary dependent variable taking the value of one if the individual appeared twice in the sample. We controlled for variables at the individual-level (age, gender, education level, current school enrollment, and employment status), variables at household-level (household size, dependency ratio and wealth), and baseline EA fixed effects. We predicted the probability of non-attrition for each woman and calculated the attrition weight as the inverse of this probability. To make the sample nationally representative, we used the sampling weights calculated by the national statistical offices and multiplied it with the attrition weight. We winsorized the weights at the top $1 \%$ level to minimize the effects of potential outliers.

\section{Results}

\section{Bivariate analyses}

Overall, $35.6 \%$ of the women used either traditional or modern contraceptive methods in 2010, while $40.4 \%$ did so in 2012 (Table 1). The use of modern contraceptives increased 
Table 1. Percent distribution of contraceptive methods and employment status in 2010 and 2012 among married women aged 15-49 years in rural Uganda.

\begin{tabular}{lrrr}
\hline & 2010 & 2012 & $p$-values \\
\hline Contraceptive methods $(\mathrm{N}=674)$ & & & \\
No contraception & 64.38 & 59.64 & .048 \\
Only traditional contraception & 11.13 & 9.50 & \\
Modern contraception & 24.50 & 30.86 & \\
Employment status $(\mathrm{N}=800)$ & & & .003 \\
Unemployed & 9.22 & 6.98 & \\
On-farm employed & 49.29 & 58.73 & \\
Off-farm wage employed & 21.49 & 13.56 & \\
Off-farm self-employed & 19.99 & 20.73 & \\
\hline
\end{tabular}

Notes: Nationally representative data using sampling weights. The sample of contraceptive methods excludes pregnant women; the sample of employment status includes all women. Traditional contraception entails withdrawal and rhythm method; modern contraception entails sterilization, IUDs, implants, injectables, pills, condoms, diaphragm, foam, standard days method and emergency contraception.

significantly from $24.5 \%$ in 2010 to $30.9 \%$ in 2012 . Some women only used traditional contraceptive methods: $11.1 \%$ in 2010 and $9.5 \%$ in 2012 .

Women's overall employment rate did not increase over time (about 91.8-93.0\%), but we noticed some changes in the type of employment (Table 1). Between 2010 and 2012, women were increasingly employed on-farm (from $49.3 \%$ to $58.7 \%$ ), while they dropped out of offfarm wage employment (from $21.5 \%$ to $13.6 \%$ ). This might have been due to the informal nature of most of the wage employment - only $6.6 \%$ of wage employees had a formal contract, and $81.0 \%$ were employed in the agricultural sector in 2010 (Table 2). The off-farm selfemployment rate remained the same over time (about 20.0-20.7\%). Women had typically been performing their jobs for a long time; they had on average 18.1 years of experience in onfarm employment, 16.3 years in off-farm wage employment and 7.7 years in off-farm selfemployment. On average, on-farm employed women worked year-round, while wage and self-employees worked fewer weeks per year (47.7 weeks and 44.2 weeks, respectively). However, during an average workweek, women who worked on their own farm did this for only $19.2 \mathrm{~h}$, while wage and self-employees worked about 30.4 and $45.8 \mathrm{~h}$, respectively.

Employed women were less likely to give birth or to be pregnant after 2 years than unemployed women, but no differences were observed in the uptake of neither traditional nor modern contraceptive methods (Table 3). Across different types of employment, we noticed significant differences for use of modern contraceptives. Off-farm wage employees were least likely to use these (23.2\%), while a greater proportion of on-farm employees $(32.5 \%)$ and off-farm self-employees $(42.1 \%)$ used such methods. No significant differences were observed for use of traditional contraception nor for giving birth/being pregnant across types of employment.

Employed women were older and less likely to be educated; they tended to have an older husband who was present fewer months in the household, and they gave birth to more children, and more of them had died (Table 4). Compared to on-farm employed women, wage employees were more likely to be educated and to have an educated, younger husband, but they were poorer and more of their children had died. Selfemployed women, on the other hand, were younger and wealthier, and had fewer (deceased) children than wage-employed women. Regarding access to contraceptives, no significant differences were observed between employed and unemployed women in 
Table 2. Employment conditions across different types of employment in 2010.

\begin{tabular}{|c|c|c|c|c|c|c|}
\hline & $\begin{array}{c}\text { On-farm } \\
\text { employed }^{(1)}\end{array}$ & $\begin{array}{l}\text { Off-farm wage } \\
\text { employed }\end{array}$ & $p$-values & $\begin{array}{l}\text { Off-farm self- } \\
\text { employed }^{(3)}\end{array}$ & $p$-values & $\underset{(2-3)}{p \text {-values }}$ \\
\hline $\begin{array}{l}\text { Work experience (years), } \\
\text { mean (se) }\end{array}$ & $18.10(0.58)$ & $16.28(0.65)$ & .042 & $7.68(0.66)$ & $<.001$ & $<.001$ \\
\hline $\begin{array}{l}\text { Weeks/year worked, mean } \\
\text { (se) }\end{array}$ & $51.45(0.20)$ & $47.71(0.94)$ & .000 & 44.24 (1.44) & $<.001$ & .045 \\
\hline $\begin{array}{l}\text { Hours/week worked, mean } \\
\text { (se) }\end{array}$ & $19.22(0.83)$ & $30.40(2.79)$ & .000 & $45.82(4.66)$ & $<.001$ & $<.001$ \\
\hline $\begin{array}{l}\text { Percent in agricultural } \\
\text { sector }\end{array}$ & 100.00 & 81.02 & .000 & .00 & $<.001$ & $<.001$ \\
\hline $\begin{array}{l}\text { Percent who worked away } \\
\text { from home }\end{array}$ & 0.00 & 100.00 & .000 & 67.93 & $<.001$ & $<.001$ \\
\hline $\begin{array}{l}\text { Percent who had formal } \\
\text { employment }\end{array}$ & 0.00 & 6.59 & .004 & 1.95 & .032 & .057 \\
\hline $\mathrm{N}$ & 398 & 183 & & 167 & & \\
\hline
\end{tabular}

Notes: Nationally representative data using sampling weights.

Table 3. Outcome variables by women's employment status in 2010 .

\begin{tabular}{|c|c|c|c|c|c|c|c|c|c|}
\hline & \multirow[b]{2}{*}{$\underset{\text { (1) }}{\text { Unemployed }}$} & \multicolumn{8}{|c|}{ Employed } \\
\hline & & $\begin{array}{c}\text { Total } \\
\text { (2) }\end{array}$ & $\begin{array}{c}p \\
\text {-values } \\
(1-2)\end{array}$ & $\begin{array}{l}\text { On-farm } \\
\text { employed } \\
\text { (3) }\end{array}$ & $\begin{array}{l}\text { Off-farm } \\
\text { wage } \\
\text { employed } \\
(4)\end{array}$ & $\begin{array}{c}p \\
\text {-values } \\
(3-4)\end{array}$ & $\begin{array}{l}\text { Off-farm } \\
\text { self- } \\
\text { employed } \\
{ }^{(5)}\end{array}$ & $\begin{array}{c}p \\
\text {-values } \\
(3-5)\end{array}$ & $\begin{array}{c}p \text { - } \\
\text { values } \\
(4-5)\end{array}$ \\
\hline $\begin{array}{l}\text { Percent who gave birth/were } \\
\text { pregnant between } 2010 \text { and } \\
2012\end{array}$ & 76.47 & 56.09 & .002 & 57.26 & 50.25 & .183 & 59.47 & .678 & .121 \\
\hline $\begin{array}{l}\text { Percent who used only traditional } \\
\text { contraception in } 2012\end{array}$ & 5.03 & 11.23 & .141 & 9.10 & 13.62 & .204 & 14.10 & .260 & .923 \\
\hline $\begin{array}{l}\text { Percent who used modern } \\
\text { contraception in } 2012\end{array}$ & 41.02 & 32.34 & .409 & 32.46 & 23.16 & .044 & 42.06 & .114 & .002 \\
\hline $\mathrm{N}$ & 52 & 748 & & 398 & 183 & & 167 & & \\
\hline
\end{tabular}

Notes: Nationally representative data using sampling weights. ${ }^{a}$ Based on a factor analysis of dwelling attributes and durable assets.

distance to the nearest town or the presence of a health center in their community, but employed women (particularly those who were on-farm employed) were more likely to have access to free contraceptives in their nearest health center. In general, women's access to contraceptives was quite low; only $19.6 \%$ lived in a community where a health center was present, and the nearest town was on average $26.4 \mathrm{~km}$ away, but if they attended a health center, $62.7 \%$ of them had access to free family planning services.

\section{Multivariate analyses}

Employment was not significantly correlated with the likelihood of giving birth or being pregnant, irrespective whether it was specified as overall employment status or as specific employment type (Table 5). However, employed women were more likely to use traditional contraceptive methods than unemployed women (adjusted odds ratio $[\mathrm{aOR}]=3.34,95 \%$ confidence interval [CI] 0.85-13.17), but no significant correlation was found between employment and the use of modern contraceptives (Table 6). Particularly off-farm wage employed women were more likely to use traditional contraception ( $\mathrm{aOR}=4.77,95 \% \mathrm{CI} 1.08-20.96$ ), while the correlation was insignificant for on-farm and off-farm self-employed women. 


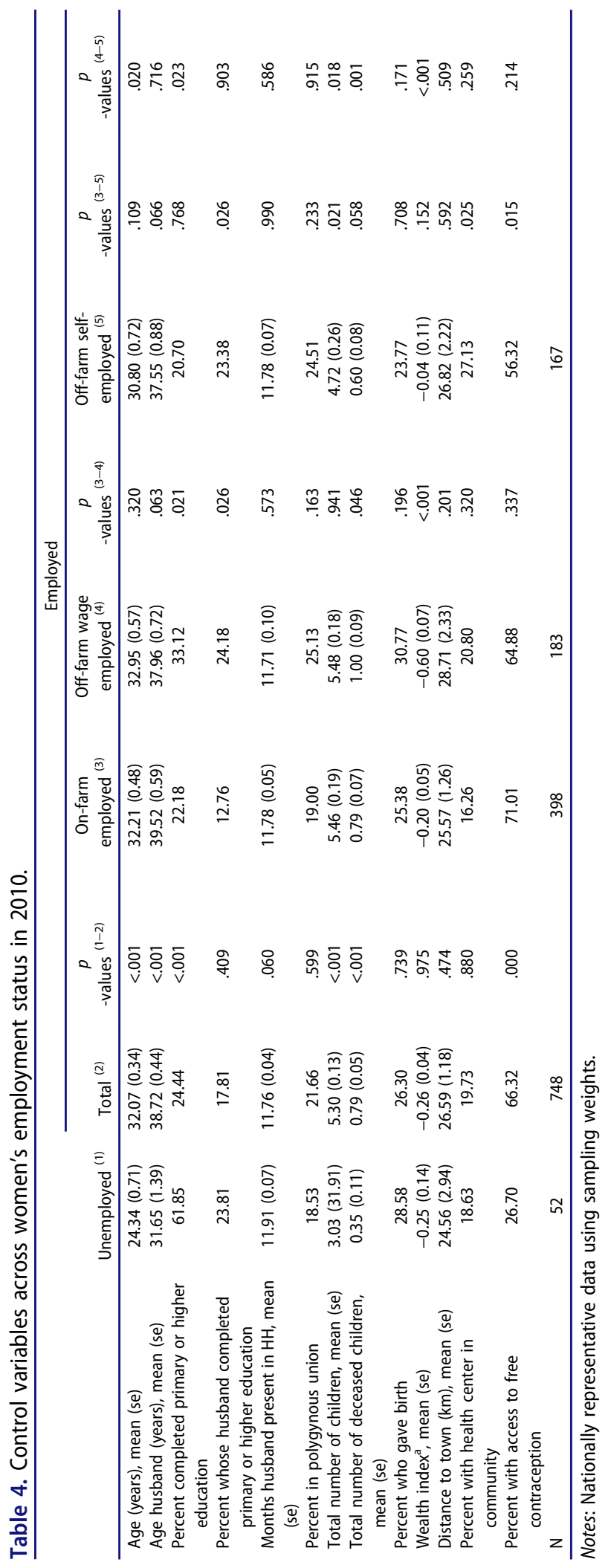


Table 5. Adjusted odds ratios [OR] (and 95\% confidence intervals [Cl]) from logistic multivariate regressions for factors associated with giving birth/being pregnant between 2010 and 2012 among married women in rural Uganda $(n=800)$.

\begin{tabular}{|c|c|c|c|c|}
\hline \multirow[b]{3}{*}{ Employed } & \multicolumn{2}{|c|}{ Model I ${ }^{\mathrm{a}}$} & \multicolumn{2}{|c|}{ Model II } \\
\hline & \multicolumn{2}{|c|}{ adj. OR $(95 \% \mathrm{Cl})$} & \multicolumn{2}{|c|}{ adj. OR $(95 \% \mathrm{Cl})$} \\
\hline & 1.22 & $(0.61-2.42)$ & & \\
\hline On-farm employed & & & 1.36 & $(0.66-2.80)$ \\
\hline Off-farm wage employed & & & 0.90 & $(0.42-1.94)$ \\
\hline Off-farm self-employed & & & 1.31 & $(0.60-2.87)$ \\
\hline Age (years) & 0.85 & $(0.81-0.90)^{* * *}$ & 0.86 & $(0.81-0.90)^{* * *}$ \\
\hline Age husband (years) & 1.00 & $(0.97-1.03)$ & 1.00 & $(0.97-1.02)$ \\
\hline Complete primary or higher & 1.18 & $(0.72-1.94)$ & 1.21 & $(0.72-2.01)$ \\
\hline Husband complete primary or higher & 0.71 & $(0.40-1.27)$ & 0.71 & $(0.40-1.28)$ \\
\hline Months husband present in $\mathrm{HH}$ & 1.42 & $(1.29-1.56)^{* * *}$ & 1.41 & $(1.29-1.56)^{* * *}$ \\
\hline Polygynous union & 0.97 & $(0.64-1.47)$ & 0.97 & $(0.63-1.47)$ \\
\hline Total number of children & 1.09 & $(0.97-1.23)$ & 1.09 & $(0.97-1.22)$ \\
\hline Total number of deceased children & 1.04 & $(0.86-1.27)$ & 1.05 & $(0.87-1.28)$ \\
\hline Gave birth in 2009 & 1.18 & $(0.78-1.80)$ & 1.20 & $(0.78-1.83)$ \\
\hline Wealth index & 0.93 & $(0.70-1.23)$ & 0.90 & $(0.68-1.18)$ \\
\hline Distance town $(\mathrm{km})$ & 1.01 & $(1.00-1.02)$ & 1.01 & $(1.00-1.02)$ \\
\hline Health center in community & 1.18 & $(0.70-1.98)$ & 1.22 & $(0.72-2.07)$ \\
\hline Access to free contraception & 1.22 & $(0.77-1.91)$ & 1.19 & $(0.76-1.89)$ \\
\hline Eastern region (base level $=$ Central region) & 1.56 & $(0.85-2.87)$ & 1.54 & $(0.84-2.84)$ \\
\hline Northern region & 1.78 & $(0.97-3.23)^{*}$ & 1.85 & $(1.01-3.41)^{* *}$ \\
\hline Western region & 0.92 & $(0.53-1.61)$ & 0.92 & $(0.53-1.60)$ \\
\hline Pseudo $R^{2}$ & 0.20 & & 0.20 & \\
\hline Likelihood ratio $\mathrm{Chi}^{2}$ & 220.44 & $* * *$ & 221.96 & $* * *$ \\
\hline Hosmer-Lemeshow $\mathrm{Chi}^{2}$ & 5.53 & & 4.58 & \\
\hline
\end{tabular}

Employment was significantly associated with the use of traditional methods for women who were older than 30 years, who had more than three children, who were wealthier, and who lived less than $30 \mathrm{~km}$ from a major town (i.e., one with more than 20,000 inhabitants) (Figure 1).

Younger women whose husband spent more time in the household and who lived in northern Uganda were more likely to give birth or to be pregnant within 2 years (Table 5). Surprisingly, whether the woman recently gave birth was not related to the short-term likelihood to give birth again. Use of traditional contraceptive methods was less frequent in Eastern and Western Uganda than in Central Uganda, and more frequent among older women and women with more children (Table 6). We did not find any other significant factors associated with the use of traditional methods. Modern contraceptive use, on the other hand, was significantly higher among wealthier women whose husband spent more time in the household and who had more children, and among women living in a community where a health center was present, and in Northern and Western Uganda. Education, husband's age and recent birth were negatively associated with use of modern contraceptives.

\section{Discussion}

The prevalence rate of contraceptive use in rural Uganda has been low, with only $40 \%$ of married women using any contraceptive method in 2012. The use of modern contraceptives did increase, however, from $25 \%$ in 2010 to $31 \%$ in 2012, which is still lower than the average of $40 \%$ in Eastern Africa (UN 2015). Nevertheless, given the short time span in 


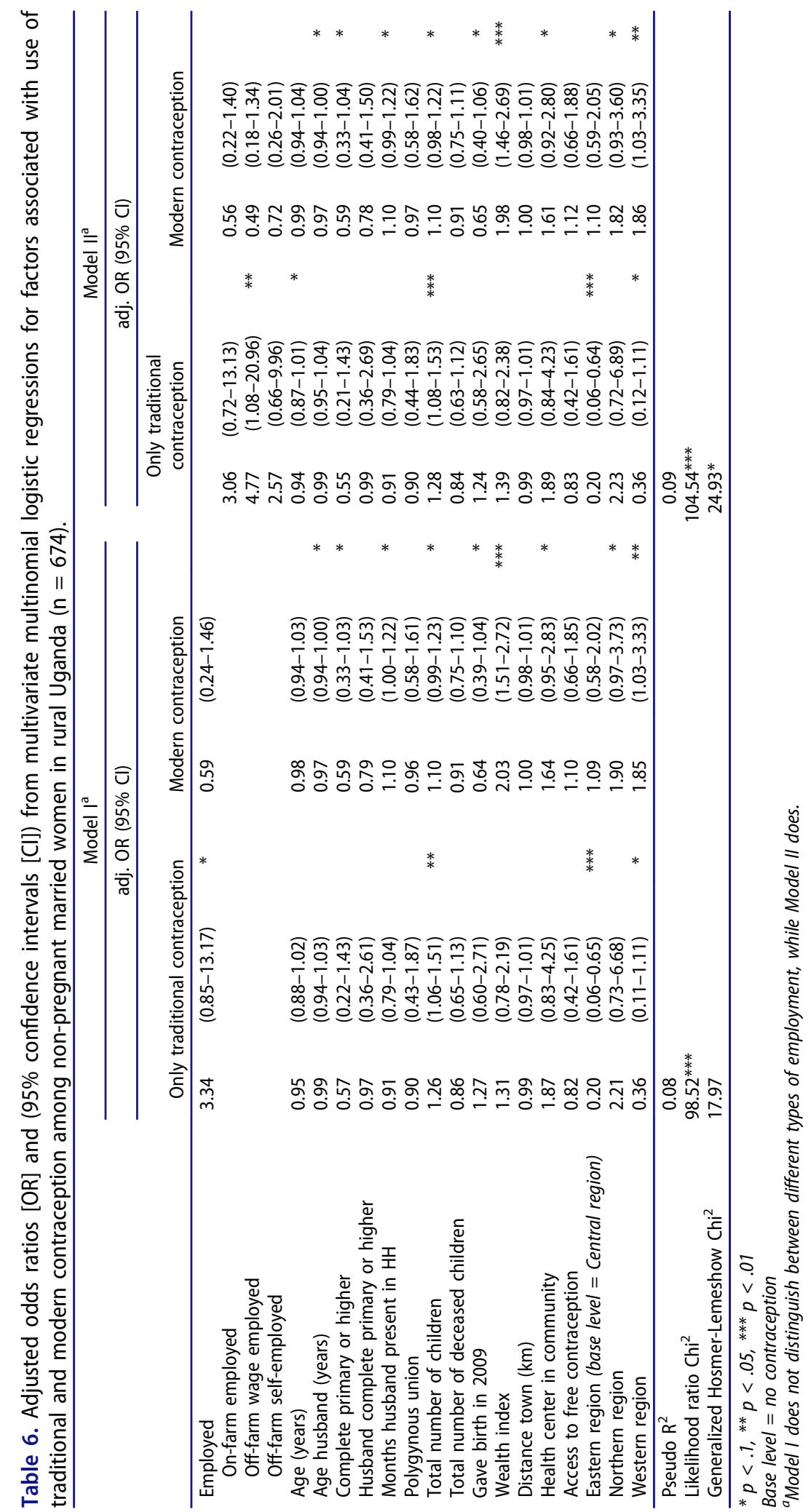



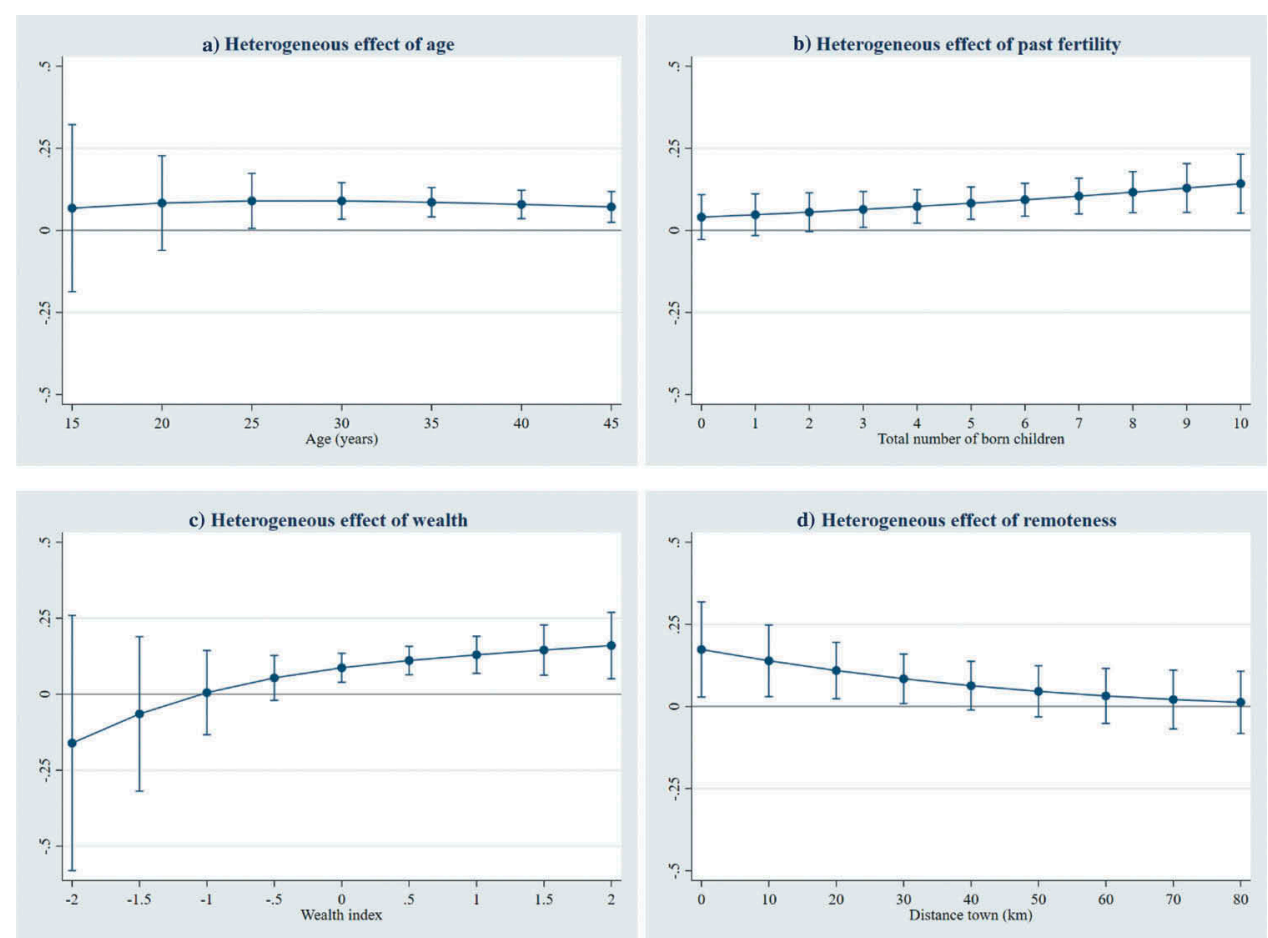

Figure 1. Average marginal effect of employment on current use of traditional contraception across various demographic characteristics: a) Age, b) Past fertility, c) Wealth, and d) Remoteness.

which the increase occurred, the higher uptake of contraceptives is promising and can be related to successful investments in programs by the government and (international) NGOs, and changing attitudes toward smaller family sizes (Eva, Quinn, and Ngo 2015; Nalwadda et al. 2010). If the rate of increase between 2010 and 2012 can be maintained during 2012-2020, the government's target of raising the use of contraception to $50 \%$ of married women might be reached by 2020. The prevalence rate derived from the UNPS was similar to the rate derived from the Uganda Demographic and Health Survey, which corroborated that our results were nationally representative (UBoS and ICF 2018).

Women's employment did not play a significant role in the increased use of modern contraceptives. This is not in line with the majority of studies that have shown that employment is associated with contraceptive use (Tiruneh et al. 2016; Wado 2017; Xu, Bentley, and Kavanagh 2011). The insignificant correlation in our study might be explained by several factors. First, unlike most other studies, we used panel data and controlled for reverse causality. Effects demonstrated by cross-sectional studies might suffer from such bias, which leads to an overestimation of the effect. Second, most studies have not distinguished between rural and urban areas, while employment differs across regions in terms of required labor skills and formality (Van den Broeck and Kilic 2019). The large majority of married women (about 60\%) who were employed in rural Uganda worked on their own farm and were not full-time employed as they typically worked 2.5 days per week, had been employed for about 12 years on average, and had not been exposed to a recent boom in off-farm employment opportunities. Only 5\% of those who were off-farm employed had a formal contract. Under 
such conditions, it was not surprising that employment was not associated with a higher uptake of modern contraceptives.

We did find that employment, and particularly off-farm wage employment, was positively correlated with the likelihood of women using traditional contraceptive methods. The increase by a factor of 4.77 was quite high, given that only $10 \%$ of the rural women used traditional methods. We did not find a significant correlation with the use of traditional methods for on-farm and off-farm self-employment. This indicated that if women earned their own income and worked away from home, they were more likely to use contraception, which was in line with studies from, for example, Tanzania (Westeneng and D'Exelle 2015), Ethiopia (Wado 2017) and Ghana (Blackstone 2017). As spouses agreed to participate in the use of traditional contraceptive methods, our findings suggested that off-farm wage employed women had a higher bargaining position within the household, and/or that they and/or their husbands had lower fertility preferences. This has been implied by Sano et al. (2018) as well, who demonstrated the importance of women's autonomy within the household to increase the uptake of contraception in the Democratic Republic of Congo.

In addition, the correlation between employment and the likelihood of using traditional contraceptive methods was stronger for particular subgroups of women. On the one hand, the correlation was strongest for women who were older than 30 years of age and who had more than four children. This suggested that particularly for women who had reached their desired fertility status, employment was associated with an increase in the use of traditional contraception. Most programs focus on delaying the age at first childbirth, but the spacing between births and the prevention of high-risk pregnancies at an older age is also important to reduce maternal and child mortality (Cleland et al. 2012). Our findings pointed to the possible role that off-farm wage employment might play in this. On the other hand, employment was not associated with the likelihood of using traditional contraceptive methods among poorer women and women who lived more remotely. This might be due to unchanged fertility preferences among employed women because of a higher dependency on off-spring in poor, remote areas (Eva, Quinn, and Ngo 2015) or due to unchanged autonomy or decision-making power within the household, as employment in poor, remote areas in rural Uganda does not necessarily empower women (Nalwadda et al. 2010).

The positive correlation between employment and use of traditional contraception on the one hand, and the insignificant correlation with modern contraceptive use on the other hand suggested an unmet need. Employed women had a higher demand for contraception, but they might still be faced with several constraints to obtain contraceptives. The supply of contraceptives and health-care programs was in general quite poor in rural Uganda during 2010-2012. However, as we controlled for various proxies for access to contraceptives, the insignificant correlation between employment and use of modern contraceptives implied that employed women faced other constraints besides a poor supply, such as capital or socio-cultural constraints (Kabagenyi et al. 2014; Nalwadda et al. 2010). In addition, women might simply have preferred traditional contraception over modern contraception, as documented by Rossier and Corker (2017) for SSA in general and by Ajayi, Adeniyi, and Akpan (2018) for Nigeria specifically.

However, traditional contraceptive methods are much less effective in preventing pregnancies than modern contraceptive methods, which might explain why employment - 
not even off-farm wage employment - was not associated with greater spacing between births. We could not deduce from this analysis whether employment eventually leads to lower total fertility rates, as documented, for example, in China (Fang et al. 2013) and Senegal (Van den Broeck and Maertens 2015). Another explanation for the insignificant correlation might be the short time span of 2 years between the two survey rounds.

Other factors were associated with the use of contraception as well. Concerning the use of modern contraceptives, we found that wealth was positively and strongly correlated, which was in line with many other studies (Sano et al. 2018; Tiruneh et al. 2016; Wado 2017). Presence of a health center in the community was also an important factor for greater use of modern contraceptives. This implied that not only demand but also supply of health-care programs was essential, which corroborated other studies (Bongaarts 2014; Nalwadda et al. 2010). Surprisingly, education was negatively correlated, which was in contrast with the majority of studies (Tiruneh et al. 2016; Wado 2017; Xu, Bentley, and Kavanagh 2011). This might be due to the very low level of schooling among married women in rural Uganda: only $22 \%$ completed primary schooling, and less than $1 \%$ completed higher education. Recently giving birth was also negatively associated with the use of modern contraceptives, which might be related to a higher reproductive health vulnerability or to a lower need if women were still breastfeeding (Westeneng and D'Exelle 2015). The use of traditional contraceptive methods was less frequent among women in Eastern and Western Uganda, which was similar to other regional statistics (UBoS and ICF 2018).

This study had some limitations. We were not able to control for women's agency or bargaining power within the household, which is likely correlated with both use of contraception and employment decisions. We did not have variables that can be used as a proxy for women's agency, so that omitted variable bias might have arisen. Therefore, we refrained from making causal statements. Nevertheless, as we controlled for reverse causality and attrition bias, and included a large set of control variables, we reduced possible bias as best as possible, which went much further in the analytic approach than has been the case in most other studies (e.g. Assefa and Tadesse 2017; Tiruneh et al. 2016; Wado 2017). Another limitation of the available data was that we could not control for religion. However, other studies have shown that religion was not significantly correlated with family planning in Uganda specifically or other neighboring countries (Andi et al. 2014; Bakibinga et al. 2016). In addition, the data did not specify whether pregnancies were planned or wanted. Finally, our analysis focused on married women aged 15-49 years in rural Uganda. This is a segment within the total female population in Uganda, so our results should not be generalized to all women in Uganda.

\section{Conclusion}

We studied the link between women's employment status and family planning decisions in rural Uganda. Using nationally representative panel data, we analyzed heterogeneous effects for different types of employment and across socio-economic characteristics. Employment was not associated with a higher use of modern contraceptives, but employed women (particularly off-farm wage employees) were more likely to use traditional contraceptive methods. Working away from home and earning a cash income might lead to a higher need for contraception than working on one's own farm, due to a possible combination of a higher income, empowerment and substitution effect. The correlation was strongest for 
women who had reached their desired fertility status, but became insignificant for poorer women who lived in more remote areas. However, due to the unmet need for family planning and the ineffectiveness of traditional contraceptive methods, off-farm wage employment was not associated with greater spacing between births.

Our findings entail policy implications for rural Uganda, which might also hold for other countries in Sub-Saharan Africa. To meet the governments' target to increase contraceptive use to $50 \%$ by 2020 , it is not sufficient to provide rural employment opportunities for women. Off-farm wage-employed women might have a higher demand for family planning, but other barriers still exist that prevent women from obtaining modern contraception. To enhance the effectiveness of family planning programs, health-care officers should target off-farm wage employed women to address their unmet need for contraception.

Our study showed the importance of using panel data and distinguishing between different employment types. The Demographic and Health Surveys (DHS), which have been conducted in more than 90 developing countries since 1984 and are the most used data source to investigate the determinants of use of contraception, do not track individuals over time, nor do they include detailed modules on women's employment. While employment is not the main focus of DHS, it is a factor that significantly affects women's lives and health. More detailed information about employment in DHS and the tracking of individuals over time might help to unravel the 'black box' behind women's employment and family planning.

\section{Notes}

1. The data are publicly available and can be retrieved from http://surveys.worldbank.org/lsms/ programs/integrated-surveys-agriculture-ISA.

2. Other survey rounds were organized in 2011 and 2014, but we did not use them because of insufficient time interval with 2010 and because $1 / 3$ of the original households were replaced in the 2014 sample.

3. A small number of observations (14) used both traditional and modern contraception. They were classified under the third level 'modern contraception' as the second level entailed women who only used traditional contraception.

\section{Acknowledgments}

The author wants to thank Miet Maertens and seminar participants at KU Leuven for their useful comments on a previous version of this paper. This research was funded by a postdoctoral fellowship from Research Foundation Flanders (FWO).

\section{Disclosure statement}

No potential conflict of interest was reported by the authors.

\section{Funding}

This work was supported by the Fonds Wetenschappelijk Onderzoek [Post-doctoral fellowship]. 


\section{ORCID}

Goedele Van den Broeck (10 http://orcid.org/0000-0002-8480-3526

\section{References}

Ajayi, A. I., O. V. Adeniyi, and W. Akpan. 2018. Use of traditional and modern contraceptives among childbearing women: Findings from a mixed methods study in two southwestern Nigerian states. BMC Public Health 18:604.

Andi, J. R., R. Wamala, B. Ocaya, and A. Kabagenyi. 2014. Modern contraceptive use among women in Uganda: An analysis of trend and patterns (1995-2011). African Population Studies 28 (2):1009-21.

Assefa, E., and M. Tadesse. 2017. Factors related to the use of antenatal care services in Ethiopia: Application of the zero-inflated negative binomial model. Women \& Health 57 (7):804-21.

Bakibinga, P., N. Mutombo, C. Mukiira, E. Kamande, A. Ezeh, and R. Muga. 2016. The influence of religion and ethnicity on family planning approval: A case for women in rural Western Kenya. Journal of Religion and Health 55 (1):192-205.

Blackstone, S. R. 2017. Women's empowerment, household status and contraception use in Ghana. Journal of Biosocial Science 49 (4):423-34.

Bongaarts, J. 2014. The impact of family planning programs on unmet need and demand for contraception. Studies in Family Planning 45 (2):247-62.

Brewster, K. L., and R. R. Rindfuss. 2000. Fertility and women's employment in industrialized nations. Annual Review of Sociology 26:271-96.

Canning, D., and P. T. Schultz. 2012. The economic consequences of reproductive health and family planning. Lancet 380:165-71.

Cleland, J., A. Conde-Agudelo, H. Peterson, J. Ross, and A. Tsui. 2012. Contraception and health. The Lancet 380 (9837):149-56.

Eva, G., A. Quinn, and T. D. Ngo. 2015. Vouchers for family planning and sexual and reproductive health services: A review of voucher programs involving Marie Stopes International among 11 Asian and African countries. International Journal of Gynecology \& Obstetrics 130:15-20.

Fang, H., K. N. Eggleston, J. A. Rizzo, and R. J. Zeckhauser. 2013. Jobs and kids: Female employment and fertility in China. IZA Journal of Labor \& Development 2 (12): 1-25.

Fruhauf, T., L. Zimmerman, S. P. S. Kibira, F. Makumbi, P. Gichangi, S. Shiferaw, A. Seme, G. Guiella, and A. Tsui. 2018. Measuring family planning quality and its link with contraceptive use in public facilities in Burkina Faso, Ethiopia, Kenya and Uganda. Health Policy and Planning 33 (7):828-39.

Goldscheider, F., E. Bernhardt, and T. Lappegard. 2015. The gender revolution: A framework for understanding changing family and demographic behavior. Population and Development Review 41 (2):207-39.

Government of Uganda. 2017. Family planning 2020 commitment.

James-Hawkins, L., C. Peters, K. VanderEnde, L. Bardin, and K. M. Yount. 2018. Women's agency and its relationship to current contraceptive use in lower- and middle-income countries: A systematic review of the literature. Global Public Health 13 (7):843-58.

Jensen, R. 2012. Do labor market opportunities affect young women's work and family decisions? Experimental evidence from India. The Quarterly Journal of Economics 127 (2):753-92.

Kabagenyi, A., L. Jennings, A. Reid, G. Nalwadda, J. Ntozi, and L. Atuyambe. 2014. Barriers to male involvement in contraceptive uptake and reproductive health services: A qualitative study of men and women's perceptions in two rural districts in Uganda. Reproductive Health 11 (1):21.

Lupu, N., and K. Michelitch. 2018. Advances in survey methods for the developing world. Annual Review of Political Science 21:195-214.

McCullough, E. B. 2017. Labor productivity and employment gaps in Sub-Saharan Africa. Food Policy 67:133-52. 
Nalwadda, G., F. Mirembe, J. Byamugisha, and E. Faxelid. 2010. Persistent high fertility in Uganda: Young people recount obstacles and enabling factors to use of contraceptives. BMC Public Health $10(1): 530$.

Prata, N., A. Fraser, M. J. Huchko, J. D. Gipson, M. Withers, S. Lewis, E. J. Ciaraldi, and U. D. Upadhyay. 2017. Women's empowerment and family planning: A review of the literature. Journal of Biosocial Science 49 (6):713-43.

Rossier, C., and J. Corker. 2017. Contemporary use of traditional contraception in sub-Saharan Africa. Population and Development Review 43 (1):192-215.

Sano, Y., R. Antabe, K. N. Atuoye, J. A. Braimah, S. Z. Galaa, and I. Luginaah. 2018. Married women's autonomy and post-delivery modern contraceptive use in the Democratic Republic of Congo. BMC Women's Health 18 (1):49.

Tigabu, D.G., and E. Villanger (2017). Labour-Intensive Jobs for Women and Development: Intrahousehold Welfare Effects and Its Transmission Channels, The Journal of Development Studies, DOI: $10.1080 / 00220388.2017 .1327661$

Tiruneh, F. N., K. Chuang, P. A. M. Ntenda, and Y. Chuang. 2016. Factors associated with contraceptive use and intention to use contraceptives among married women in Ethiopia. Women \& Health 56 (1):1-22.

Uganda Bureau of Statistics (UBOS). 2010. The Uganda national panel survey (UNPS) 2009/10 basic information document. Kampala, Uganda: UBOS.

Uganda Bureau of Statistics (UBOS) and ICF. 2018. Uganda demographic and health survey 2016. Kampala, Uganda and Rockville, Maryland, USA: UBOS and ICF.

United Nations, Department of Economic and Social Affairs, Population Division. 2015. Trends in contraceptive use worldwide 2015. ST/ESA/SER.A/349.

Van den Broeck, G., and M. Maertens. 2015. Female employment reduces fertility in rural Senegal. PloS One 10 (3):e0122086.

Van den Broeck, G., and T. Kilic. 2019. Dynamics of off-farm employment in Sub-Saharan Africa: A gender perspective. World Development 119:81-99.

Vyas, S., J. Mbwambo, and L. Heise. 2015. Women's paid work and intimate partner violence: Insights from Tanzania. Feminist Economics 21 (1):35-58. doi:10.1080/13545701.2014.935796.

Wado, Y. D. 2017. Women's autonomy and reproductive healthcare-seeking behavior in Ethiopia. Women \& Health. doi:10.1080/03630242.2017.1353573.

Westeneng, J., and B. D'Exelle. 2015. How economic empowerment reduces women's reproductive health vulnerability in Tanzania. The Journal of Development Studies 51 (11):1459-74.

Xu, Y., R. J. Bentley, and A. M. Kavanagh. 2011. Gender equity and contraceptive use in China: An ecological analysis. Women \& Health 51 (8):739-58. 